\title{
Cholestasis-lymphedema syndrome
}

INSERM

\section{Source}

INSERM. (1999). Orphanet: an online rare disease and orphan drug data base.

Cholestasis-lymphedema syndrome. ORPHA:1414

Cholestasis-lymphedema syndrome is a rare genetic disorder characterized by neonatal intrahepatic cholestasis, often lessening and becoming intermittent with age, and severe chronic lymphedema which mainly affects the lower limbs. Patients often present with fat malabsorption leading to failure to thrive, fat soluble vitamin deficiency with bleeding, rickets, and neuropathy. In $25 \%$ of cases, cirrhosis occurs during childhood or later in life. 